\section{Preventing decay in children: dare we risk the 'risk assessment' model in practice?}

\author{
K. M. Milsom ${ }^{1}$ and M. Tickle ${ }^{2}$
}

IN BRIEF

- Is targeted dental prevention for caries in children better than a public health approach in the practice setting?

- Implementation of the public health approach requires minimal diagnostic skills, is inexpensive, but will provide prevention to many who may not require it.

- Until we have a reliable way of assessing which children will develop caries, the population approach offers the greater likelihood of success.

Encouraging dental prevention seems like a logical approach given that dental decay is a preventable disease and while the 2006 dental contract provides preventive opportunities, there is confusion about the best approach to the prevention of decay in those children that attend their dentist. Should we provide prevention for all children attending their dentist (the population approach) or should we target those children who are at greatest risk (risk assessment approach)?

In terms of tackling the population/risk based argument, we need to be clear about the relative merits and costs of each approach.

By providing the whole population (that attends a dentist) with evidence-based prevention, there is a clear expectation that disease levels will decrease, but in offering it to everyone it has to be acknowledged that some individuals receiving prevention will not benefit since they were never going to develop the disease in the first place. Further, if the cost of prevention is high for each individual that receives it, then the population approach, while effective, may well offer poor value for money.

The argument for a risk assessment model appears a far more elegant and sensible way forward. By identifying those at greater risk of developing disease we are able to limit the intervention to those most likely to benefit, thereby reducing costs yet achieving effective reductions in population disease levels. This approach was recently advocated in the British Dental Journal. ${ }^{1}$

\footnotetext{
${ }^{*}$ Consultant/Honorary Professor of Population Oral Health, Oral Health Unit, National Primary Care R\&D Centre, Halton \& St Helens Primary Care Trust; ${ }^{2}$ Professor of Dental Public Health \& Primary Care, Oral Health Unit, National Primary Care R\&D Centre, University of Manchester

${ }^{*}$ Correspondence to: Professor Keith Milsom

Email: keith.milsom@hsthpct.nhs.uk
}

\section{Refereed Pape}

Accepted 8 July 2010

DOI: 10.1038/sj.bdj.2010.720

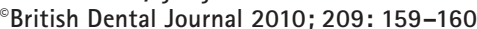

We believe that a dual approach to prevention is required and indeed, this is exactly what the preventive toolkit Delivering better oral health: an evidence based toolkit for prevention advocates to practitioners. The toolkit calls for all those attending dental practice to receive a basic level of prevention (population approach) with those deemed to be at increased risk, ie caries active, being recommended to receive an enhanced intervention (risk assessment approach).

What we need clarity about (and we do not yet have it) are the relative merits of the population and the risk assessment approaches. The population approach offers the potential for success if evidencebased prevention is delivered. On the other hand the risk assessment approach alone will only work if the method used to assess 'risk' is sound. The authors of a recent $B D J$ article themselves claim that 'caries risk prediction is far from perfect.' This understates the true position. There is clear evidence that general dental practitioners are quite unable to identify which children are likely to develop decay. Research has shown that $25 \%$ of young, regularly attending children with no caries at first presentation at their NHS dentist go on to develop the disease within three years. The research also shows that three out of four children presenting with the disease at their first visit go on to develop further lesions over a three-year period. ${ }^{2}$

Dentists have limited ability to identify those caries free children likely to develop decay and have been equally unimpressive in their ability to prevent the advance of disease once it has developed. ${ }^{3-5}$ Despite this, the authors are proposing a system which relies on these two skills, albeit with a painstaking assessment of caries in enamel. This disappointing track record of caries risk assessment by NHS dentists simply cannot be used as the basis of a cogent approach to the prevention of caries in children.

The dental profession has a limited grasp of how caries in the child population behaves over time. There is a dearth of good longitudinal epidemiology in this area. What is becoming clear from the limited available data ${ }^{2}$ is that there is a fundamental difference between the majority of young children that are caries free and those that are caries active. Research shows that the caries free state in these children is a precious one, because once caries begins, its inexorable development is assured. Notwithstanding this, the authors appear to advocate a forensic investigative campaign to find 'early caries'. This represents a very significant investment in the most expensive resource in dentistry, namely dentists' time with no evidence that this use of resource produces the desired outcomes. It means that we are applying a very expensive intervention to the whole population (a time consuming and costly microscopic examination by dentists) rather than a less costly preventive intervention to the whole population by dental nurses.

A more optimistic approach must be to take the view that we have the tools to 
prevent the disease getting to the stage when it has an impact on quality of life, ie post-cavitation stage. Most importantly, we are able to prevent this disease from appearing in a significant proportion of the child population. Provided that these tools are relatively inexpensive they should be used on all children. of course, this approach does not require serried ranks of eagle-eyed dentists, because extended duty dental nurses are able to deliver effective prevention. Population dental prevention is a good opportunity for developing the concept of skill mix within the dental profession. This is to be encouraged.

If the evidence-based, population approach to the prevention of caries in children is encouraged and large numbers of children retain their caries free state as a consequence, there will still be the need to target that small number in the child population for whom the "entry level' of prevention is insufficient to prevent the onset of caries. Targeting this small but interesting group and understanding the reasons why its members succumb to caries is important. There is a need for high quality research in this area.

Clearly there are risk factors for childhood caries, but our understanding of them is poor. According to Page et al all we can say with confidence is that the presence of caries is the best predictor of new lesions. Given that this disease is preventable, it is a sad indictment of the risk assessment model that its basic premise is that failure in prevention is the trigger for the introduction of prevention. The population approach, on the other hand, takes a more optimistic stance. It takes the caries free state as its starting point and attempts to maintain this position using evidence based interventions. Along the way, some children will needlessly receive preventive care, but in the great scheme of things is it unacceptable to 'overprevent', if we are able to prevent caries developing in large numbers of children? Of course once there is in place a reliable tool for predicting caries, then the risk assessment model will take centre stage. In the meantime the logic is inescapable - an evidence-based population approach must remain the cornerstone of prevention.

The authors are part of a multidisciplinary team that has received $£ 1.7$ million funding from the Health Technology Programme of NIHR to measure the costs and effects or preventing caries in young children attending general dental practice. For further information see: http://www.hta.ac.uk/1970.

1. Page J, Weld J A, Kidd E A M. Caries control in health service practice. Br Dent J 2010; 208: 449-450.

2. Milsom K M, Blinkhorn A S, Tickle M. The incidence of dental caries in the primary molar teeth of young children receiving National Health Service funded dental care in practices in the North West of England. Br Dent J 2008; 205: E14.

3. Tickle M, Milsom K M, King D, Blinkhorn A S. The influences on preventive care provided to children who frequently attend the UK General Dental Service. Br Dent J 2003; 194: 329-332.

4. Threlfall A G, Hunt C M, Milsom K M, Tickle M, Blinkhorn A S. Exploring factors that influence general dental practitioners when providing advice to help prevent caries in children. Br Dent J 2007; 202: E10.

5. Threlfall A G, Milsom K M, Hunt C M, Tickle M, Blinkhorn A S. Exploring the content of the advice provided by general dental practitioners to help prevent caries in young children. Br Dent J 2007; 202: E9. 